\title{
Perspectives on Teaching Approaches and the Grade Point Average Attainment of Undergraduate Medical Students at University of Zambia
}

\author{
Harrison Daka*, Charles M. Namafe, Patricia Katowa - Mukwato \\ Department of Medical Education Development, School of Medicine, University of Zambia, Lusaka, Zambia \\ *Corresponding Author: Harrison Daka, Department of Medical Education Development, School of \\ Medicine, University of Zambia, Lusaka, Zambia
}

\begin{abstract}
Over the years since its inception, the University of Zambia, School of Medicine remained a premier academic institution that prided itself with exceptionally high outcomes and graduates of high caliber. However, despite such accolades, and during the course of the focus of this study from 2008 to 2016 there were low students Grade Point Average (GPA) among undergraduate programmes in the School of Medicine of the University of Zambia (Field data, 2018). In order to delve this issue, this study investigated the relationship between teaching approaches and the students' GPA among undergraduate medical students trained at the University of Zambia, School of Medicine during the years from 2008 to 2016.

A mixed methods approach involving qualitative and quantitative methods was employed to investigate the above mentioned issue. An explanatory sequential research design was used for data collection. Data were captured from using an evaluation survey instrument, students' Focus Group Discussion schedule and an in depth interview schedule for key informants regarding the GPA. Quantitative data from the first set were analysed using descriptive and inferential statistics while qualitative data from the second set were analysed using constant comparative method.

The study revealed that the following contributed to low GPA in the School of Medicine at the University of Zambia during the period under study:

(a) there was inadequate teaching and learning (b) concepts were not explained in depth which led to students' perceptions that courses were difficult. (c) despite having well qualified lecturers (54.7\%) students were not availed with handbooks (62.6\%) and course curriculum (53\%).There was no significant statistical difference among the programmes $(p=.663, F=4,596, d f=.600)$.

In conclusion, the study shows that low students' GPA at the Medical School of the University of Zambia was due to among other things inappropriate teaching approaches. In view of these findings, the study recommends that enrolment of students should be dependent on availability of infrastructure and facility capacities and that the Department of Medical Education and Development (DMED) should consider organizing specific pedagogical training programmes for existing and newly employed academic staff.
\end{abstract}

Keywords: Teaching approaches, Grade Point Average, Quality Teaching and Students outcomes

\section{INTRODUCTION}

This study aimed at by establishing the relationship between teaching approaches and Grade Point Average (GPA) in the School of Medicine at the University of Zambia. In 2017, the University of Zambia transformed the Medical School into four new schools, namely, School of Public Health, School of Health Sciences, School of Nursing Sciences and School of Medicine. This study's findings refer to a period between 2008 and 2016 before the institution split up. The study was done through the evaluation of the rating of teaching contributions. The idea for the study stems from the phenomena observed by the researcher that, despite the School of Medicine having projects like the Department for International Development (DFID) from 1995 to 2000 and Medical Education Partnership Initiative (MEPI) from 2011 to 2015 which aimed at improving the quality of teaching.

Grades in any course are dependent on students' performance and the Grade Point Equivalent is used to determine a student's Grade Point Average. From the 2015/2016 academic year, the University of Zambia adopted the grading system shown in Table 1.1 below. 
Perspectives on Teaching Approaches and the Grade Point Average Attainment of Undergraduate Medical Students at University of Zambia

Table1.1: Scoring and Grade Point Value System

\begin{tabular}{|l|l|l|l|}
\hline \multicolumn{1}{|c|}{ Letter Grade } & \multicolumn{1}{c|}{ Description } & \multicolumn{1}{c|}{ Mark Range } & Grade Point Value \\
\hline $\mathrm{A}+$ & DISTINCTION & $90-100$ & 5 \\
\hline $\mathrm{A}$ & DISTINCTION & $80-89$ & 4 \\
\hline $\mathrm{B}+$ & MERITORIOUS & $70-79$ & 3.5 \\
\hline $\mathrm{B}$ & CREDIT & $60-69$ & 3 \\
\hline $\mathrm{C}+$ & CREDIT & $50-59$ & 2.37 \\
\hline $\mathrm{C}$ & PASS & $45-49$ & 1.5 \\
\hline $\mathrm{D}+$ & FAIL & $40-44$ & 0 \\
\hline $\mathrm{D}$ & FAIL & $<40$ & 0 \\
\hline
\end{tabular}

Source: Field Data, 2018

Low Grade Point Average (GPA) is a growing concern in most higher learning institutions [1]. From the School of Medicine, the GPA and examination attrition rates for the years 2008 and 2014 were analysed and the following were discovered.

The 2008-2014 students' GPA from the School of Medicine at the University of Zambia shown in Table 1.2 below indicated that the GPA was on average 2.41 with the lowest GPA values coming from the year 2008 with 2.16 and the highest was from the year 2014 with 2.85 .

Table1.2: Grade Point Averages from 2008 to 2014

\begin{tabular}{|l|l|l|l|l|l|l|l|}
\hline YEAR & $\mathbf{2 0 0 8}$ & $\mathbf{2 0 0 9}$ & $\mathbf{2 0 1 0}$ & $\mathbf{2 0 1 1}$ & $\mathbf{2 0 1 3}$ & $\mathbf{2 0 1 4}$ & OVERALL \\
\hline AVERAGE & 2.16 & 2.57 & 2.28 & 2.43 & 2.18 & 2.85 & 2.41 \\
\hline
\end{tabular}

Source: Field Data, 2018

[2]defines educational quality as a situation where there are student outcomes that encompass knowledge, skills and attitudes, and are linked to national goals for education and positive participation in society. Quality learner outcomes are intentional expected effects of the educational system [3]. They include what students know and can do, as well as the attitudes and expectations they have for themselves and their societies. Student achievement results are important indicators of educational quality. Where there is educational quality, the students' outcomes include among others high Grade Point Average [4].

In higher learning institutions high GPA is a primary goal though [5] states that improvements in attaining it seem to be ineffective. In most universities in the United States of America (USA), research shows that slightly over $50 \%$ of the students complete their degrees within the years though their GPA is slightly high [6]. The higher GPA for students indicates to the outside community the quality of education offered in the medical school [7].

\section{QUALITY TEACHING VS QUALITY LEARNING}

\subsection{Quality Learning}

\subsubsection{Personalized Learning}

It is stated that no two individuals learn in the same way, nor do they bring the same prior knowledge to a learning experience [8]. This means that for quality of learning to take place, there is need to use a variety of teaching strategies. [9] added that the concept of personalizedlearning builds mainly on the cognitive and constructivist theories of learning. Unlike behaviourist learning theory, cognitive learning theory proposes that information processing is governed by an internal process [10]. Some examples and applications of cognitive learning theory include discussion and problem solving among many other teaching approaches. On the other hand constructivist learning theory is based on the premise that learners are to construct their own perspective of the world based on their own individual experiences and internal knowledge. The theory advocates that since everyone has a different set of experiences and perceptions, teaching then must be unique and different for each person. Constructivist instructional theory requires that instructional designers determine which instructional methods and strategies would help learners to acquire understanding. During the instructional designing, it is important to put into consideration different approaches to learning and teaching so that all learners are helped in acquiring the required knowledge quality [11]. It is thus clear that management of teaching and learning activities is a component in educational quality. 
Perspectives on Teaching Approaches and the Grade Point Average Attainment of Undergraduate Medical Students at University of Zambia

\subsubsection{Socially Constructed Learning}

The theory of learning best fit in socially constructed learning is Situated Learning Theory. This theory posits that learning is unintentional and situated within authentic activity, context, and culture [12]. Therefore, it is important that knowledge is presented in an authentic context (settings and situations that would normally involve that knowledge). Students learn through interaction with others and the physical world. When students learn something that is not connected to the physical environment, they mostly forget and even lose interest in the concept. The collaboration, peer-tutoring and reciprocal teaching that occurs when students work together results in a deeper understanding of the material being covered. Hence it is suggested that if students work in groups as peers, they get motivated to work harder and perform better in examinations [13], [14]. This is one of the factors which contribute to quality education. In this way, each presenter does more reading on the subject matter thereby gaining more understanding[12]. From the above, it can be concluded that when students work in groups as peers, it contributes to educational quality.

\subsubsection{Differentiated Learning}

The prior knowledge we all bring to a task means individuals require different levels of challenge, pace, content and context. [15] from his study in the USA among secondary schools stated that with differentiated instruction, students with different learning abilities can acquire quality education in a general education classroom. This requires lecturers to plan well for such types of lessons and to state the lesson objectives in order to offer the teaching that will achieve learning. This also requires standard-based instructional context with helpful instructional strategies and real-life examples. Therefore, teaching characteristics play a major role in bringing about quality of education.

\subsubsection{Learning that is Initiated by Students Themselves}

This type of learning is referred to as self-regulated learning. This is the type of learning where learners set goals for their learning and later attempt to monitor, regulate, and control their cognition, motivation, behaviour and the guidance of the environment [12], [10]. [16] also suggest that for this to be achieved, lessons need to be designed in such a way that students initiate the learning process in accordance with their educational goals and personal aspirations. In this case, it is acceptable to redirect students to do programmes which they did not choose as their personal aspirations are shattered.

\subsection{Teaching Approaches}

\subsubsection{Teaching Characteristics}

It has been stated by some authors in medical education that the most contributing factor to students' good performance has been the type of instruction received during the course of learning and the continual evaluation and monitoring of courses [3]. [17],[3] state that low quality teaching of an educator will have a negative impact on the performance of the students and the level of understanding of the course content contributes to students' attrition rate. [18] argues that learning is an active process. Problem-based, or inquiry-based, learning has gained a strong foothold in health science education. Most learners especially adults lose interest in an educational experience without the incorporation of active learning. [19] also agrees with the aforementioned author that active engagement in an experience promotes critical thinking skills and improves long-term retention of content. [20] also adds that active learning increases motivation and interest in the learning domain. Another research done by [21] considered past examination results and demonstrated that improvement in critical thinking, improved cognitive retention and enhanced clinical decision-making correlated with low examination rates.

A learner-centred approach requires the instructor to adjust instructional strategies to best meet the needs of their students [22]. [23] insist that it is important to develop strong and supportive relationships within the course to increase student comfort with the instructors and each other. The process of achieving this relies on the learning strategies used. 


\subsubsection{Supervision}

Another principle under teaching practices involves supervision which lecturers offer to students. Similarly, factors such as instructor preparation/organization, clarity, availability, and helpfulness; the quality and frequency of feedback provided to students; and instructor rapport with students all positively and significantly promote course content acquisition and mastery. Specifically, [24] demonstrated links between good teacher behaviours (e.g., clarity, organized presentation of material) and lower examination attrition rate. [25] found a positive link between active teaching pedagogies (e.g., classroom discussion) and higher Grade Point Average. The principle of supervision and support of students suggests that faculty members are in a good position to guide students (Chickering and Gamson's (1987). In addition, [26] emphasize that when people are expected to do well, with guidance and support they will succeed.

\section{Problem Statement}

There is, therefore, need to clarify and interpret the interaction of the characteristics of the structure and culture of the undergraduate programmes that perpetuate high loss rates and low GPA which lies at <2.0 [27]. The 2003 self-evaluation against the WFME (World Federation for Medical Education) standards also showed that the School of Medicine did not meet the required score in all the areas of the WFME International Standards for Basic Medical Education. Hence finding ways to decrease attrition rates and produce students with high GPA is critical both from an economical and quality point of view.

\section{PURPoSe OF THE STUdY}

The purpose of this study was to investigate staff and students' perspectives on the relationship between teaching approaches and the GPA among undergraduate health professions students of the University of Zambia.

\subsection{Research Objective}

From the purpose of the study, the objective of the study was to explore staff and students' views regarding the teaching approaches used for undergraduate students at the institution.

\section{Methodology}

This study used the explanatory sequential design mixed methods in a diagnostic way. In explanatory sequential design the researcher begins by conducting a quantitative phase and follows up on specific results for the purpose of explaining the initial results in depth [28]. It is this focus on explaining results that is reflected in the design name.

The purpose of the design is to use a qualitative strand to explain initial quantitative results [29]. The design is most useful when the researcher wants to assess trends and relationships with quantitative data and to explain the phenomenon leading to the trends. In this study, this was chosen because the low GPA of the students was not understood. Therefore, using this design the researcher hoped to explain the causes that led to the scenario. The data collected was then analysed from one paradigm and later the other. For instance, in this study, the researcher first collected the quantitative data, analysed it and later collected the qualitative data, analysed it and finally did the interpretation.

The basic rationale for this design was that one data collection paradigm would supply strengths to offset the weaknesses of the other paradigm and provide a complete understanding of the research problem. Document analysis was first done. Survey questionnaires were administered by the researcher while other respondents filled online. Schedules for FGD and In - depth interviews were later done. Research assistants were trained in data entry. Data analysis used was descriptive analysis, one way ANOVA, Chi - square, Measurement of association and comparative method.

In this case, the data collected from the quantitative method was verified and triangulated with the data from the qualitative methods. Figure 1.1 shows a visual illustration of how the exploratory sequential design was applied. 
Perspectives on Teaching Approaches and the Grade Point Average Attainment of Undergraduate Medical Students at University of Zambia

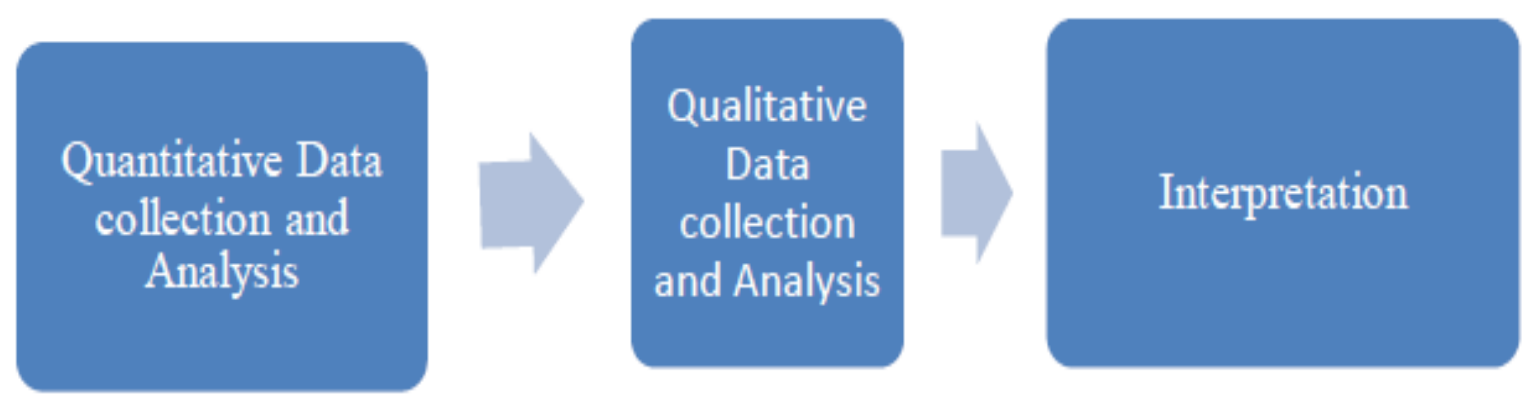

Figure1.1: Illustrations of Explanatory Sequential Design

Source: Adapted from [30]

\section{FINDINGS AND DISCUSSION}

The study looked at quality teaching and learning in the context of whether students were availed with course curriculum, handbooks and teaching schedule and whether the teaching academic staff were qualified. [31], [32] indicate that lecturer qualification has a bearing on students' achievement and this is in line with the University of Zambia policy that only those with a minimum of Masters' Degree qualify to lecture undergraduate students. In this study, the findings were in agreement with these scholars [31], [32] that the qualification of the lecturers contribute to the performance of the students.

In the case of course curricula, $47 \%$ of the respondents agreed that the lecturers availed the students with course curricular and only $37.4 \%$ agreed that lecturers availed the students with handbooks. The data which was obtained from in-depth interviews and self-evaluation questionnaires revealed that some of the academic staff were not oriented by Heads of Department in the courses they were to teach. In short there was no induction at all. In some cases, the lecturers were not availed with the whole curriculum making it difficult to know the limits and extents of coverage especially in relation to other topics in other departments. The study by [33] went further to state that most academic staff after their academic study were not given the tools needed to succeed in bringing about student achievement. Thus [34] propose that after initial training, the academic staff need to undergo a programme to connect the content covered in training to the actual teaching needs through identification of specific types of training needs for improving student achievement. This study emphasises lecturer induction before the actual teaching as a way of improving quality education.

The study also evaluated teaching characteristics as one of the variables to quality teaching. [35] emphasises that teachers need to show commitment to teaching through being punctual to class and attending to all classes. In this study, it was revealed that $56.6 \%$ students valued the lectures they attended and would not have managed the courses without classes. This means that most students depended on lecturers' guidance in explaining the concepts for them to understand. [36] states that it is not just attending to classes that matters but what the lecturer does and says to students would determine whether the students perform well or not. In this study, students observed that $54 \%$ of the lecturers did not state the objectives clearly at the beginning of each lesson and this made it difficult for students to follow.

In addition, the study considered teaching characteristics of academic staff in terms of attending to classes, punctuality, and use of ICT in teaching and whether students could cope without attending classes. The study further showed that some lecturers did not give updated information on the subject matter and normally just read slides without explaining the concepts. One lecturer was cited as, "He is seen to have shallow understanding of the course and does not promote critical thinking" while one was cited not to follow the course schedule and would repeat the lesson on the use of ICT. The study also revealed that most of the lecturers (63.2\%) used ICT in the teaching while few others still used the "ancient methods of teaching using chalk board" and never gave chance to students to copy.

However, even some of those who used ICT just read the slides without explaining. ICT provides many opportunities for constructivist learning through the provision and support for resource-based student centred and enable learning to be related to context and practice. 
Perspectives on Teaching Approaches and the Grade Point Average Attainment of Undergraduate Medical Students at University of Zambia

[37] highlights instructional strategies as a major contributor to students' good academic performance. It is stipulated in their study that an effective educator would have a wide array of instructional strategies at their disposal and know when specific strategies are to be used for specific students and specific content. Management of teaching and learning activities also involves time management and motivation (Chickening and Gamson's, 1987). The summary of how students performed in different courses is shown in the tables below.

Table1.3: Courses with appropriate teaching approaches

\begin{tabular}{|l|l|}
\hline \multicolumn{1}{|c|}{ Course Code } & \multicolumn{1}{c|}{ Overall Grade Point Average } \\
\hline HAN 2600 & 3.0 \\
\hline PTY 4410 & 3.2 \\
\hline PTY 5140 & 3.4 \\
\hline ESH 5440 & 4.0 \\
\hline BMS 2115 & 3.7 \\
\hline PMY 4329 & 3.7 \\
\hline
\end{tabular}

Source: Field Data, 2018

Table1.4: Courses with inappropriate teaching approaches

\begin{tabular}{|l|l|}
\hline \multicolumn{1}{|c|}{ Course Code } & \multicolumn{1}{c|}{ Overall Grade Point Average } \\
\hline PMY 2010 & 1.1 \\
\hline PGY 2030 & 0.4 \\
\hline BMS 3325 & 2.0 \\
\hline PMY 5710 & 2.5 \\
\hline PGY 4110 & 0.5 \\
\hline PMT 4210 & 1.0 \\
\hline
\end{tabular}

Source: Field Data, 2018

\section{CONCLUSION AND RECOMMENDATION}

From the findings above, it was confirmed that there was an association between teaching practices of academic staff and the graduation rates of undergraduate students at the Medical School of the University of Zambia. It was clear that management of teaching and learning and the teaching characteristics of staff contributed to the graduation rates of undergraduate students. In order to mitigate this challenge, the medical school needed to train its entire academic staff in pedagogy and make sure that all newly employed staff underwent induction before they commenced actual teaching and that the enrolment of students should be dependent on availability of infrastructure and facility capacities

\section{REFERENCES}

[1] Tyler-Smith, K. (2010). Early Attrition among First Time e Learners: A Review of Factors that Contribute to Drop-out, Withdrawal and Non-completion Rates of Adult Learners undertaking eLearning Programmes. Christchurch, Christchurch Polytechnic Institute of Technology.

[2] UNICEF (2000). Defining Quality in Education. New York, UNICEF

[3] Kane, T. J., Rockoff, J. E., \&Staiger, D. O. (2006). What does certification tell us about teacher effectiveness? Evidence from New York City (Working Paper 12155). Cambridge, MA: National Bureau of Economic Research

[4] Shelton, E. (2003). Faculty support and student retention. Journal of Nursing Education 42(2): 68-76

[5] Steedle, J. T. (2007) Improving the reliability and interpretability of value-added scores for postsecondary institutional assessment programmes. Paper presented at the American Educational Research Association annual meeting, Denver, CO,

[6] Berkner, L., He, S., \&Cataldi, E. (2002). Descriptive summary of 1995-96 beginning postsecondary students: Six years later (Statistical Analysis Report No. 2003-151). Washington, DC: U.S. Department of Education, Office of Educational Research and Improvement, National Center for Education Statistics.

[7] Schafer, L. (2003). What can we do about e-dropouts? Training and Development 56 (6) 40-46

[8] Farmer, E. A. (2004). Faculty development for problem-based learning.European Journal of Dental Education, 8(2), 59-66. 
Perspectives on Teaching Approaches and the Grade Point Average Attainment of Undergraduate Medical Students at University of Zambia

[9] Sampson, D. \& Karagiannidis, C. (2010). Personalised learning: Educational, technological and standardisation perspective. Interactive educational multimedia, (4), 24-39.

[10] Schunk, D. H. (2005). Self-regulated learning: The educational legacy of Paul R. Pintrich. Educational Psychologist, 40, 85-94.

[11] Osborne, M. (2013). Modern learning Environments. London, Routledge.

[12] Zimmerman, C. M. (2011). Does learning with high-fidelity human patient simulation (HFHPS) in nursing school impact career retention in the nursing profession during the first two years of licensure? Kansas City, Missouri

[13] Boekaerts, M., \&Cascallar, E. (2006). How far have we moved toward the integration of theory and practice in self-regulation? Educational Psychology Review, 18, 199-210.

[14] Wolters, C. A. (2003). Regulation of motivation: Evaluating an underemphasized aspect of self-regulated learning. Educational Psychologist, 38(4), 189-205.

[15] Lawrence-Brown, D. (2004). Differentiated instruction: Inclusive strategies for standards-based learning that benefit the whole class. American secondary education, 34-62.

[16] Puntambekar, S., \&Hubscher, R. (2005). Tools for scaffolding students in a complex learning environment: What have we gained and what have we missed? Educational psychologist, 40(1), 1-12.

[17] Rice, J. (2003). Teacher quality: understanding the effectiveness of teacher attributes. Washington D. C., Institute of Economic Policy

[18] Hovancsek, M.T. (2007). Using simulations in nursing education. In: P.R. Jeffries (Ed.) Simulation in Nursing Education: From Conceptualization to Evaluation. National League for Nursing, New York; 1-9.

[19] Billings, D.M., \& Halstead, J.A. (2005). Teaching in nursing: A guide for faculty (2nd ed). Philadelphia: W.B. Sauders.

[20] Cioffi, J. (2005). A pilot study to investigate the effect of a simulation strategy on the clinical decision making of midwifery students.Journal of Nursing Education, 44(3), 131-134.

[21] Gordon, J.A., Brown, D.F.M, and Armstrong, E.G. (2006). Can a simulated critical care encounter accelerate basic science learning among preclinical medical students? A pilot study.Simulation in Healthcare, 1, 13-17.

[22] Allen, R.E. (2016). Preadmission Predictors of On-time Graduation in a Doctor of Pharmacy Programme, American Journal of Pharmaceutical Education; 80 (3), 1- 43.

[23] Diaz, D.P. (2001). Online drop rates revisited. The Technology Source. (May/June) [Online.] [viewed 24/08/2013]

[24] Braxton, J. M., Milem, J. F., \& Sullivan, A. S. (2000). The influence of active learning on the college student departure process: Toward a revision of Tinto's theory. The Journal of Higher Education, 71, 569590.

[25] Braxton, J. M., (Ed.). (2008). The role of the classroom in college student persistence. New Directions for Teaching and Learning, No. 115. San Francisco: Jossey-Bass.

[26] Jeffries, P.R. (Ed.). (2007). Simulation in nursing education: From conceptualization to evaluation. New York: National League for Nursing.

[27] Banda, S.S. (2004). The Role of Anatomy in Clinical Practice: A participant Observation Study of Anatomy in Clinical Practice. Medical Journal of Zambia 35: (1) 8-15

[28] Subedi, D. (2016). Explanatory Sequential Mixed Method Design as the Third Research Community of Knowledge Claim.American Journal of Educational Research, 4(7), 570-577.

[29] Creswell, J. W. and Clark, V. L. (2011). Designing and Conducting Mixed Methods Research (2nd ed). ThosandOrks, CA: Sage.

[30] Brannen, J. (2005) Mixed methods Researcher: A discussion paper; NCRM methods review papers. Viewed on 30 June, 2017 from ncrm, uk/publications/documents.

[31] Wayne, A. J. \&Youngs, P. (2003). Teacher characteristics and student achievement gains: A review. Review of Educational Research, 73, 89-122.

[32] Goe, L. (2007). The link between teacher quality and student outcomes: A research synthesis. Washington, DC: National Comprehensive Center for Teacher Quality.

[33] Levine, A. (2006). Educating school teachers. Washington, DC: The Education Schools Project.

[34] Zeichner, K. M., \& Conklin, H. G. (2005). Teacher education programmes. In M. Cochran-Smith \& K. M. Zeichner (Eds.), Studying teacher education: The report of the AERA panel on research and teacher education (pp. 645-736). Mahwah, NJ: Lawrence Erlbaum Associates. 
Perspectives on Teaching Approaches and the Grade Point Average Attainment of Undergraduate Medical Students at University of Zambia

[35] Johnson, S. M., \&The Project on the Next Generation of Teachers. (2004). Finders and keepers: Helping new teachers survive and thrive in our schools. San Francisco, CA: Jossey-Bass.

[36] Yoon, K. S., Duncan, T., Lee, S. W.-Y., Scarloss, B., \& Shapley, K. (2007). Reviewing the evidence on how teacher professional development affects student achievement (Issues \& Answers Report, REL 2007No. 033). Washington, DC: U.S. Department of Education.

[37] Lamon, S. J. (2012). Teaching fractions and ratios for understanding: Essential content knowledge and instructional strategies for teachers. New York, Routledge.

Citation: Harrison Daka, et.al. "Perspectives on Teaching Approaches and the Grade Point Average Attainment of Undergraduate Medical Students at University of Zambia". International Journal of Humanities Social Sciences and Education (IJHSSE), vol. 6, no.12, 2019, pp. 75-82. doi: http://dx.doi.org/ 10.20431/2349-0381.0712006.

Copyright: (C) 2019 Authors. This is an open-access article distributed under the terms of the Creative Commons Attribution License, which permits unrestricted use, distribution, and reproduction in any medium, provided the original author and source are credited. 